\title{
Risk of pneumonia and urinary tract infection within the first week after total hip arthroplasty and the impact on survival
}

This article was published in the following Dove Press journal:

Clinical Epidemiology

23 January 2017

Number of times this article has been viewed

\author{
Eva N Glassou ${ }^{1,2}$ \\ Torben B Hansen ${ }^{1,3}$ \\ Alma B Pedersen ${ }^{2}$ \\ 'University Clinic of Hand, Hip \\ and Knee Surgery, Department of \\ Orthopedic Surgery, Regional Hospital \\ West Jutland, Aarhus University, \\ ${ }^{2}$ Department of Clinical Epidemiology, \\ Aarhus University Hospital, ${ }^{3}$ The \\ Lundbeck Foundation Centre for \\ Fast-track Hip and Knee Replacement, \\ Aarhus University, Aarhus, Denmark
}

Correspondence: Eva Natalia Glassou University Clinic of Hand, Hip and Knee Surgery, Department of Orthopedic Surgery, Regional Hospital West Jutland, Aarhus University, Lægårdvej 12 , DK-7500 Holstebro, Denmark

Tel +45 78438706

Email evagla@rm.dk
Background: Pneumonia and urinary tract infections (UTIs) increase morbidity and mortality. There is little epidemiological evidence from large population-based studies on risk factors for these infections and subsequent mortality in total hip arthroplasty (THA) patients.

Aim: To examine the risk factors of postoperative pneumonia and UTI after THA and their impact on survival.

Patients and methods: We used the Danish Hip Arthroplasty Register to identify THAs due to osteoarthritis registered from 2000 to 2013. We collected data about comorbidities, mortality and infections in relation to primary hospitalization and potential predictive variables from administrative databases. Regression models were used to estimate associations between potential risk factors and infection, and subsequently, between infection and mortality.

Results: In total 84,812 THAs were included. The cumulative incidence of pneumonia and UTI within 7 days of the primary procedure were 0.21 (95\% confidence interval [CI]: $0.18-0.25$ ) and 0.29 (95\% CI: 0.26-0.33), respectively. Patient-related risk factors for infection were being 80 years or older, gender and a comorbidity burden at time of surgery. The hazard ratio (HR) of dying within 90 days of the primary THA was 10.67 (95\% CI: 5.79-19.57) compared to patients without pneumonia. For patients with UTIs, the HR was 1.64 (95\% CI: 0.41-6.59) compared to those without a UTI.

Conclusion: Pneumonia was associated with an increased short-term risk of dying, despite adjustment for coexisting comorbidity and other potential confounders. Age, gender and comorbidity were the most important risk factors for pneumonia and UTIs. Individual initiatives to reduce the risk of pneumonia in select patient groups may be essential to the effort to optimize outcomes after a THA.

Keywords: total hip arthroplasty, pneumonia, urinary tract infection, mortality, risk factor, prognosis

\section{Background}

Although total hip arthroplasty (THA) procedures are considered beneficial and safe, complications, such as pneumonia and urinary tract infections (UTIs), still occur. In THA patients, short-term readmission or incidence rates due to pneumonia or UTIs are reported to be less than $2-5 \% .^{1-5}$ Despite the low frequencies, pneumonia and UTIs are strenuous and may, especially in patients with a high comorbidity burden, be critical.

Pneumonia and UTIs are associated with increased morbidity and mortality. ${ }^{6-9}$ Both infections are seen more often in elderly persons and in persons with other comorbidities - and in patients who are in need of a THA. ${ }^{8,10}$ Pneumonia was, combined with 
influenza, the 9th most frequent cause of death in the US in $2010,{ }^{11}$ and the incidence of hospitalization with pneumonia has increased during the past years. ${ }^{12-14}$ In the US in 2005, UTIs were responsible for $15.5 \%$ of infectious disease hospitalizations in citizens aged 65 years or older; this rate was exceeded only by pneumonia. ${ }^{8}$ Additionally, UTIs were the most frequent hospital-acquired infection, primarily due to catheterization. ${ }^{9}$ Development of infections such as pneumonia or UTIs are not without risks, and there is reason to believe that an infection in combination with the primary procedure only deteriorates the prognosis after THA.

Improved knowledge about the occurrence and risk factors for pneumonia and UTIs is, therefore, of importance in the individual risk stratification each clinician performs when counseling patients before a THA. Hence, the aim of this study was to identify the risk factors of postoperative pneumonia and UTIs after THA and their impact on subsequent patient survival.

\section{Patients and methods}

The Danish Hip Arthroplasty Register (DHR) formed the basis of the study. The DHR holds individual data including the diagnosis, primary procedures and revisions for all THA procedures performed in Danish public or private hospitals since $1996 .{ }^{15,16}$ The DHR is an example of high-quality, prospectively collected data suitable for population-based epidemiology studies. The completeness in 1994 was $97.8 \%$ for primary procedures. ${ }^{17}$

Based on the unique 10-digit personal identification number (CPR) encoding age, sex and date of birth that all citizens in Denmark are assigned at birth, each procedure from the DHR was linked to the Danish National Patient Register (DNPR). Each record in the DNPR contains the patient's CPR number, information on treatment procedures, surgical procedures, and primary discharge diagnoses and up to 20 secondary discharge diagnoses on all inpatient admissions to Danish hospitals since 1977 and outpatient visits since 1995. ${ }^{18}$ Diagnoses are coded according to the International Classification of Diseases (ICD), revision 8 from 1977 to 1994 and ICD, revision 10 thereafter. The primary procedures have further been linked to the Danish Civil Registration System (CRS). The CRS maintains records of residence and date of death of all Danish citizens from April 1968 and onward and is updated daily. ${ }^{19}$ The CPR number acted as the identifier when establishing the final dataset. Standard cleaning and preparation of the dataset with the removal of implausible values were performed. The study protocol and analysis plan are available from the corresponding author upon request.

\section{Study population}

We included all primary THAs from 2000 to 2013 due to osteoarthritis (OA) (Figure 1). 7,404 patients had operations on both hips (688 simultaneously). This corresponds to $14,408(17 \%)$ of the 84,812 included THAs.

\section{Infections}

Information about pneumonia and UTIs was collected using the DNPR. The following ICD codes were used: pneumonia: DJ12-DJ18; UTI: DN30.0, DN30.8 and DN30.9. As early postoperative infections in direct connection with surgery and hospitalization may be considered preventable, all cases of pneumonia and UTIs registered in relation to the primary hospitalization for THA or during a readmission within 7 days of the primary THA were included. The validity of the coding of both pneumonia and UTI in the DNPR has been examined in the Danish context. The positive predictive value for pneumonia was $90-93 \%$. For UTIs, it was $77 \%$. $^{20,21}$ By looking at cases within 7 days, we focused on the very early postoperative infections directly connected to surgery and hospitalization.

\section{Risk factors for infections}

Potential and available risk factors for pneumonia and UTIs are presented in Table 1. Age at the time of THA was divided into five categorical groups: 10-49, 50-59, 60-69, 70-79 and $80+$ years. Comorbidity was measured with the Charlson Comorbidity Index (CCI). ${ }^{22}$ All primary and secondary diagnoses from hospitalizations and outpatient visits registered in the DNPR over a 10-year period before the primary THA

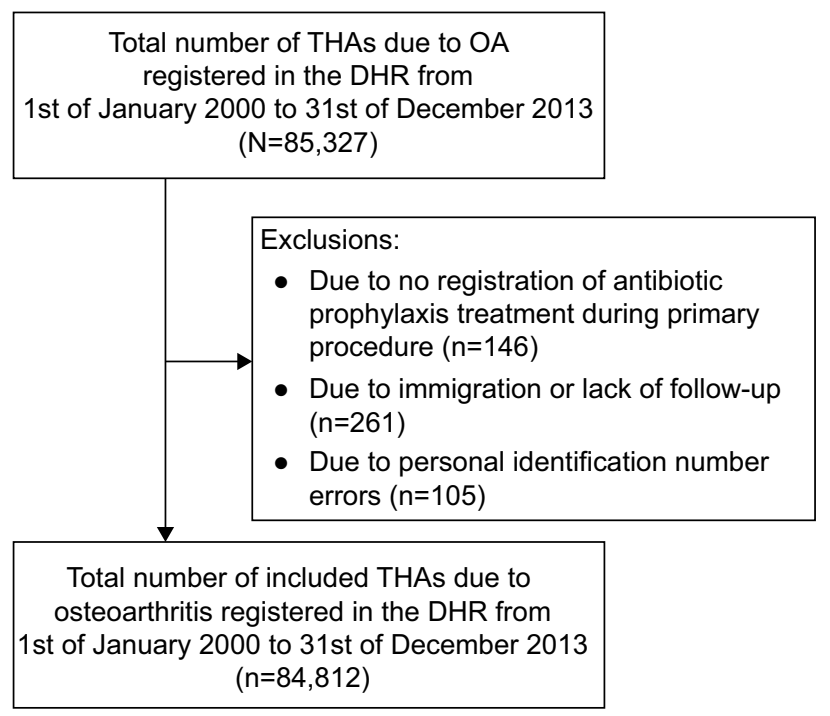

Figure I Flow chart for study population. In total, 84,812 total hip arthroplasty (THA) procedures due to osteoarthritis (OA) were included ( $99.4 \%$ of total available). Abbreviation: DHR, The Danish Hip Arthroplasty Register. 
Table I Number of pneumonia and urinary tract infections (UTIs) within 7 days of the primary total hip arthroplasty

\begin{tabular}{|c|c|c|c|}
\hline Patient characteristics & $\begin{array}{l}\text { Procedures } \\
N=84,812(\% \text { of } N)\end{array}$ & $\begin{array}{l}\text { Pneumonia within } 7 \text { days } \\
n=172(\% \text { of } N)\end{array}$ & $\begin{array}{l}\text { UTI within } 7 \text { days } \\
n=235(\% \text { of } N)\end{array}$ \\
\hline \multicolumn{4}{|l|}{ Year of surgery } \\
\hline 2000-2004 & $23,904(28.18)$ & $24(0.10)$ & $59(0.25)$ \\
\hline 2005-2009 & $32,07 I(37.8 I)$ & $54(0.17)$ & $106(0.33)$ \\
\hline $2010-2013$ & $28,837(34.00)$ & $94(0.33)$ & $70(0.24)$ \\
\hline \multicolumn{4}{|l|}{ Gender } \\
\hline Female & $47,678(56.22)$ & $72(0.15)$ & $168(0.35)$ \\
\hline Male & $37,134(43.78)$ & $100(0.27)$ & $67(0.18)$ \\
\hline \multicolumn{4}{|l|}{ Age (years) } \\
\hline $10-49$ & $2,923(3.45)$ & I (0.03) & $3(0.10)$ \\
\hline $50-59$ & $11,363(13.40)$ & $13(0.11)$ & $15(0.13)$ \\
\hline $60-69$ & $28,784(33.94)$ & $26(0.09)$ & $63(0.22)$ \\
\hline $70-79$ & 30,101 (35.49) & $82(0.27)$ & $99(0.33)$ \\
\hline $80+$ & $|I, 64|(\mid 3.73)$ & $50(0.43)$ & $55(0.47)$ \\
\hline \multicolumn{4}{|l|}{ Comorbidity } \\
\hline CCl-none & $57,680(68.01)$ & $67(0.12)$ & $136(0.24)$ \\
\hline CCl-low & $13,079(15.42)$ & $43(0.33)$ & $42(0.32)$ \\
\hline $\mathrm{CCl}$-medium & $8,931(10.53)$ & $28(0.3 \mathrm{I})$ & $33(0.37)$ \\
\hline CCl-high & $5,122(6.04)$ & $34(0.66)$ & $24(0.47)$ \\
\hline \multicolumn{4}{|l|}{ Specific comorbidity } \\
\hline Diabetes & $4,083(4.8 I)$ & $2 \mathrm{I}(0.5 \mathrm{I})$ & I5 (0.37) \\
\hline COPD & $4,983(5.88)$ & $40(0.80)$ & $18(0.36)$ \\
\hline \multicolumn{4}{|l|}{ Laterality } \\
\hline One hip & 70,404 (83.01) & $|4|(0.20)$ & $198(0.28)$ \\
\hline Both hips & 14,408 (16.99) & $31(0.22)$ & $37(0.26)$ \\
\hline \multicolumn{4}{|l|}{$\mathrm{LOPH}$} \\
\hline $1-3$ & $29,252(34.49)$ & $72(0.25)$ & $56(0.19)$ \\
\hline $4-7$ & $30,130(35.53)$ & $61(0.20)$ & $103(0.34)$ \\
\hline $8+$ & $25,430(29.98)$ & $39(0.15)$ & $76(0.30)$ \\
\hline \multicolumn{4}{|c|}{ Duration of surgery (minutes) ${ }^{\mathrm{a}}$} \\
\hline$<60$ & $43,914(51.78)$ & $83(0.19)$ & $85(0.19)$ \\
\hline$\geq 60$ to $<120$ & $39,185(46.20)$ & $84(0.21)$ & $137(0.35)$ \\
\hline$\geq 120$ & $\mathrm{I}, 544(\mathrm{I} .82)$ & $4(0.26)$ & $12(0.78)$ \\
\hline \multicolumn{4}{|l|}{ Fixation - cup ${ }^{\mathrm{a}}$} \\
\hline Cemented + antibiotics & $20,404(24.10)$ & $51(0.25)$ & $69(0.34)$ \\
\hline Cemented - antibiotics & $\mathrm{I}, 507(\mathrm{I} .18)$ & I $(0.07)$ & $5(0.33)$ \\
\hline Uncemented & $62,758(74.12)$ & $120(0.19)$ & $159(0.25)$ \\
\hline \multicolumn{4}{|l|}{ Fixation - stem ${ }^{\mathrm{a}}$} \\
\hline Cemented + antibiotics & $36,829(43.58)$ & $89(0.24)$ & $126(0.34)$ \\
\hline Cemented - antibiotics & $2,105(2.49)$ & $\mathrm{I}(0.05)$ & $6(0.29)$ \\
\hline Uncemented & $45,575(53.93)$ & $81(0.18)$ & $101(0.22)$ \\
\hline \multicolumn{4}{|c|}{ Hospital volume (procedures per year) } \\
\hline $\mathrm{I}-50$ & $3,203(3.78)$ & $6(0.19)$ & $10(0.31)$ \\
\hline $51-100$ & $7,519(8.87)$ & $15(0.20)$ & $24(0.32)$ \\
\hline $10 \mid-200$ & $15,127(17.84)$ & $25(0.17)$ & $54(0.36)$ \\
\hline $20 I-300$ & $10,593(12.49)$ & $27(0.25)$ & $36(0.34)$ \\
\hline $301+$ & $48,370(57.03)$ & $99(0.20)$ & $\mathrm{III}(0.23)$ \\
\hline \multicolumn{4}{|l|}{ Approach } \\
\hline Posterior & 77,089 (90.89) & $165(0.21)$ & $226(0.29)$ \\
\hline Anterior + lateral & $7,723(9.11)$ & $7(0.09)$ & $9(0.12)$ \\
\hline
\end{tabular}

Notes: Comorbidity is measured with the Charlson Comorbidity Index $(\mathrm{CCl})$. Equal scores of $\mathrm{CCl}$ are as follows: $\mathrm{CCl}$-none: 0; $\mathrm{CCl}$-low: I; CCl-moderate: 2; and CCl-high:

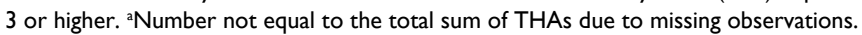

Abbreviations: COPD, chronic obstructive pulmonary disease; LOPH, length of primary hospitalization.

formed the basis of the CCI calculation. The CCI score was calculated by adding the points of each disease category for each procedure and was categorized into 4 CCI groups
(CCI-none, CCI-low, CCI-moderate and CCI-high). Diabetes and chronic obstructive pulmonary disease (COPD) were included as specific comorbid conditions. Laterality as an 
indicator of the severity of OA was considered a potential risk factor. Structure-related risk factors were length of primary hospitalization (LOPH) and annual hospital volume. LOPH was divided into 3 groups (0-3 days, 4-7 days and $8+$ days). An LOPH of more than 30 days was considered to be primarily a registration error and was recoded as 31 days. The annual hospital volumes were divided into the following groups: $1-50,51-100,101-200,201-300$ and $>300$ primary THAs per year based on the number of primary THAs due to OA in each hospital in the year of the procedure. Surgeryrelated risk factors were the duration of surgery, the type of fixation and the surgery approach. Duration of the primary procedure was categorized into 3 groups ( $<60$ minutes, $\geq 60$ to $<120$ minutes and $\geq 120$ minutes). The type of fixation was divided into 6 groups, 3 for each of the implants. The acetabulum cup data were categorized as cemented cups with or without antibiotics and uncemented cups. The femoral stem was divided into cemented stems with or without antibiotics and uncemented stems. The surgery approach was divided into the posterior approach and anterior/lateral approaches. Information about the duration of surgery, the type of fixation and the approach were collected using the DHR.

\section{Mortality}

Information on all-cause mortality was obtained from the CRS. In an attempt to avoid immortal time bias during the first week (the period where patients develop infections), we looked at short-term mortality (the number who died between 8 and 90 days postoperation, given that the patient was alive on day 7) and long-term mortality (the number who died between 91 and 365 days after surgery, given that the patient was alive during the short-term interval).

\section{Statistics}

We tabulated the characteristics of the study population in total and in relation to infection. Age and LOPH were described as medians with an interquartile range (IQR). The risks of pneumonia and UTI within 7 days of surgery were calculated as cumulative incidences with $95 \%$ confidence intervals (CIs) and death as a competing risk. A logistic regression model was used to examine the association between potential risk factors and pneumonia and UTIs. We estimated an odds ratio with $95 \%$ CIs for each potential risk factor mutually adjusted for all other potential risk factors. When analyzing the effect of diabetes and COPD, adjustments were made for all other diagnoses in the CCI. We calculated the short-term and longterm risks of mortality using a Cox regression model to obtain hazard ratios (HRs) for death with 95\% CIs comparing THA patients with and without pneumonia or UTIs. The same covariates and analog categorization as in the examination of potential risk factors for infections were used in this analysis of association between infection and mortality.

The analyses were performed using the Stata Statistical Software (Release 12.0; StataCorp LP, College Station, TX, USA).

\section{Ethics}

Permission to process personal data was obtained from the Danish Data Protection Agency (reference number: 201241-0636). In Denmark, patient consent is not required in register based research; the permission from the Danish Data Protection Agency is sufficient.

\section{Results}

A total of 172 patients $(0.2 \%)$ developed pneumonia and 235 $(0.3 \%)$ developed a UTI within 7 days of surgery. In 5 procedures, both infections were present. The number of patients with infections stratified by demographic characteristics is shown in Table 1. The median age was 69.8 years (IQR: 62.9-76.2) for patients without pneumonia or a UTI. The median age for patients with pneumonia was 75.8 years (IQR: 70.2-80.7) and was 74.0 years (IQR: $66.3-79.5)$ for patients with a UTI. Of the total population, $56 \%$ were females. For patients with pneumonia, the percentage of females was $42 \%$. For patients with a UTI, the percentage of females was $71 \%$. The median LOPH for patients without pneumonia or a UTI within 7 days of the primary THA was 5 days (IQR: 3-8), whereas the median LOPH for those with pneumonia was 4 days (IQR: 3-7). For patients developing a UTI, the median LOPH was 6 days (IQR: 4-8).

The cumulative incidence rates of pneumonia and UTIs within 7 days of the primary procedure were 0.21 (95\% CI: $0.18-0.25)$ and 0.29 (95\% CI: 0.26-0.33), respectively. The cumulative incidence rate of pneumonia increased during the study period from 0.10 (95\% CI: 0.06-0.15) in 2000-2004 to 0.32 (95\% CI: $0.26-0.39$ ) in 2010-2013. For UTIs, the risk did not significantly differ during the study period and ranged from 0.25 (95\% CI: $0.19-0.32)$ in $2000-2004$ to 0.24 (95\% CI: 0.19-0.30) in 2010-2013.

\section{Risk factors for infection}

The analyses of risk factors are presented in Table 2. Patientrelated risk factors for pneumonia and UTIs within 7 days included gender, being 80 years or older and a comorbidity burden measured with CCI. While age and the comorbidity burden acted identically in both infections, where an increase 
Table 2 Risk factors for pneumonia and urinary tract infection (UTI) within 7 days of primary total hip arthroplasty

\begin{tabular}{|c|c|c|c|c|}
\hline \multirow[t]{2}{*}{ Risk factors } & \multicolumn{2}{|c|}{ Pneumonia within 7 days } & \multicolumn{2}{|l|}{ UTI within 7 days } \\
\hline & Crude OR (95\% Cl) & Adjusted OR (95\% Cl) & Crude OR (95\% Cl) & Adjusted OR (95\% Cl) \\
\hline \multicolumn{5}{|l|}{ Gender } \\
\hline Female & Reference & Reference & Reference & Reference \\
\hline Male & $1.79(1.32-2.42)$ & $1.85(1.36-2.53)$ & $0.5 \mathrm{I}(0.38-0.68)$ & $0.53(0.40-0.7 I)$ \\
\hline \multicolumn{5}{|l|}{ Age (years) } \\
\hline $10-49$ & $0.13(0.02-0.90)$ & $0.15(0.02-1.06)$ & $0.31(0.10-0.98)$ & $0.33(0.10-1.04)$ \\
\hline $50-59$ & $0.42(0.23-0.75)$ & $0.48(0.26-0.89)$ & $0.40(0.23-0.69)$ & $0.4 \mathrm{I}(0.23-0.73)$ \\
\hline $60-69$ & $0.33(0.2 \mathrm{I}-0.5 \mathrm{I})$ & $0.35(0.22-0.55)$ & $0.66(0.48-0.91)$ & $0.69(0.49-0.69)$ \\
\hline 70-79 & Reference & Reference & Reference & Reference \\
\hline $80+$ & $1.58(1.11-2.25)$ & $1.60(|| I-2.31)$. & $1.44(1.03-2.00)$ & $1.44(1.03-2.01)$ \\
\hline \multicolumn{5}{|l|}{ Comorbidity $\mathrm{CCl}$} \\
\hline CCl-none & Reference & Reference & Reference & Reference \\
\hline CCl-low & $2.84(1.93-4.16)$ & $2.40(1.62-3.54)$ & $1.36(0.96-1.93)$ & $1.27(0.90-1.80)$ \\
\hline $\mathrm{CCl}$-medium & $2.70(1.74-4.21)$ & $2.22(1.42-3.47)$ & $1.57(1.07-2.30)$ & $1.42(0.97-2.09)$ \\
\hline CCl-high & $5.75(3.80-8.69)$ & $4.32(2.82-6.61)$ & $1.99(1.29-3.08)$ & $1.69(1.08-2.65)$ \\
\hline \multicolumn{5}{|l|}{ Specific comorbidity } \\
\hline Diabetes $^{\mathrm{a}}$ & $2.56(1.75-4.36)$ & $2.11(1.32-3.35)$ & $1.35(0.80-2.28)$ & $1.22(0.72-2.07)$ \\
\hline $\mathrm{COPD}^{\mathrm{a}}$ & $4.89(3.43-6.97)$ & $4.03(2.80-5.79)$ & $1.33(0.82-2.15)$ & $1.09(0.66-1.80)$ \\
\hline \multicolumn{5}{|l|}{ Laterality } \\
\hline One hip & Reference & Reference & Reference & Reference \\
\hline Both hips & $1.07(0.73-1.59)$ & $1.03(0.70-1.53)$ & $0.91(0.64-1.30)$ & $0.96(0.89-1.86)$ \\
\hline \multicolumn{5}{|l|}{ LOPH (days) } \\
\hline $1-3$ & Reference & Reference & Reference & Reference \\
\hline $4-7$ & $0.82(0.58-1.16)$ & $0.71(0.49-1.01)$ & $1.79(1.29-2.48)$ & $1.48(1.05-2.07)$ \\
\hline $8+$ & None & None & None & None \\
\hline \multicolumn{5}{|c|}{ Duration of surgery (minutes) } \\
\hline$<60$ & Reference & Reference & Reference & Reference \\
\hline$\geq 60$ to $<120$ & $1.13(0.84-1.54)$ & $1.18(0.84-1.67)$ & $1.81(1.38-2.37)$ & $1.73(1.28-2.34)$ \\
\hline$\geq 120$ & $1.37(0.50-3.75)$ & $1.65(0.59-4.63)$ & $4.04(2.20-7.4 I)$ & $4.43(2.35-8.37)$ \\
\hline \multicolumn{5}{|l|}{ Fixation - acetabulum } \\
\hline Cemented + antibiotics & Reference & Reference & Reference & Reference \\
\hline Cemented - antibiotics & $0.26(0.04-1.92)$ & $1.00(0.07-15.30)$ & $0.98(0.40-2.44)$ & $1.56(0.34-7.14)$ \\
\hline Uncemented & $0.76(0.55-1.06)$ & $1.06(0.69-1.64)$ & $0.75(0.56-0.99)$ & $1.35(0.94-1.94)$ \\
\hline \multicolumn{5}{|l|}{ Fixation - stem } \\
\hline Cemented + antibiotics & Reference & Reference & Reference & Reference \\
\hline Cemented - antibiotics & $0.20(0.03-I .4 I)$ & $0.25(0.02-3.82)$ & $0.83(0.37-1.89)$ & $0.64(0.16-2.56)$ \\
\hline Uncemented & $0.73(0.54-0.99)$ & $0.97(0.63-1.48)$ & $0.65(0.50-0.84)$ & $1.16(0.81-1.65)$ \\
\hline \multicolumn{5}{|c|}{ Hospital volume (procedures per year) } \\
\hline $1-50$ & $0.92(0.40-2.09)$ & $1.14(0.50-2.65)$ & $1.36(0.7 \mid-2.60)$ & $1.62(0.84-3.14)$ \\
\hline $51-100$ & $0.97(0.57-1.68)$ & $1.21(0.68-2.13)$ & $1.39(0.89-2.17)$ & $1.40(0.88-2.23)$ \\
\hline $10 \mid-200$ & $0.81(0.52-1.25)$ & $0.83(0.52-1.31)$ & $1.56(1.12-2.16)$ & $1.53(1.08-2.15)$ \\
\hline $20 I-300$ & $1.25(0.8 I-1.91)$ & $1.16(0.74-1.8 I)$ & $1.48(1.02-2.16)$ & $1.43(0.97-2.10)$ \\
\hline $30 \mathrm{I}+$ & Reference & Reference & Reference & Reference \\
\hline \multicolumn{5}{|l|}{ Approach } \\
\hline Posterior & Reference & Reference & Reference & Reference \\
\hline Anterior + lateral & $0.42(0.20-0.90)$ & $0.48(0.22-1.03)$ & $0.40(0.20-0.77)$ & $0.42(0.2 \mathrm{I}-0.87)$ \\
\hline
\end{tabular}

Notes: Risk estimates involve crude and adjusted odds ratios (ORs) with confidence intervals (Cls) mutually adjusted for all other potential risk factors. Comorbidity measured with the Charlson Comorbidity Index $(\mathrm{CCl})$. ${ }^{\text {Reference }}=$ not having diabetes or COPD. Adjustments encompassed, in addition to other potential risk factors, all other comorbid conditions included in the $\mathrm{CCl}$.

Abbreviations: COPD, chronic obstructive pulmonary disease; LOPH, length of primary hospitalization.

in age or comorbidity burden increased the risk of infection, gender acted differently. Male gender was a risk factor for pneumonia and female gender was a risk factor for UTIs. Both diabetes and COPD were risk factors for pneumonia but not for UTIs. No association between laterality and the risk for UTIs or pneumonia was observed.
Few surgery or structural related risk factors were identified as risk factors for UTI. Duration of surgery of more than 60 minutes and a posterior approach increased the risk of UTI. LOPH of more than 3 days and a hospital volume between 101 and 200 procedures per year acted as risk factors for UTI. 
Table 3 Short-term (8-90 days following primary procedure) and long-term (9I-365 days following primary procedure) mortality risks with corresponding hazard ratios (HRs), comparing patients with either pneumonia or urinary tract infection (UTI) with those without pneumonia or UTI

\begin{tabular}{|c|c|c|c|c|}
\hline Infections & Patients at risk, $n$ & Mortality, n (\%) & Crude HR $(95 \% \mathrm{Cl})$ & Adjusted HR $(95 \% \mathrm{Cl})$ \\
\hline \multicolumn{5}{|c|}{ Short-term mortality, 8-90 days } \\
\hline Without pneumonia & 84,532 & $312(0.37)$ & I.00 (reference) & I.00 (reference) \\
\hline Pneumonia & 167 & $14(8.38)$ & $19.21(10.53-35.06)$ & $10.67(5.79-19.57)$ \\
\hline Without UTI & 84,465 & $324(0.38)$ & 1.00 (reference) & 1.00 (reference) \\
\hline UTI & 234 & $2(0.85)$ & $2.28(0.57-9.15)$ & $\mathrm{I} .64(0.4 \mathrm{I}-6.59)$ \\
\hline \multicolumn{5}{|c|}{ Long-term mortality, $91-365$ days } \\
\hline Without pneumonia & 84,220 & $860(1.02)$ & I.00 (reference) & I.00 (reference) \\
\hline Pneumonia & 153 & $7(4.58)$ & $4.60(2.18-9.67)$ & $2.56(1.21-5.39)$ \\
\hline Without UTI & $84,|4|$ & $861(1.02)$ & 1.00 (reference) & 1.00 (reference) \\
\hline UTI & 232 & $6(2.59)$ & $2.56(1.14-5.70)$ & $1.84(0.82-4.12)$ \\
\hline
\end{tabular}

Notes: HR estimates are presented with $95 \%$ confidence intervals (Cls). Adjustments are made for gender, age, comorbidity, laterality, length of stay, duration of surgery, type of fixation, annual hospital volume and surgical approach.

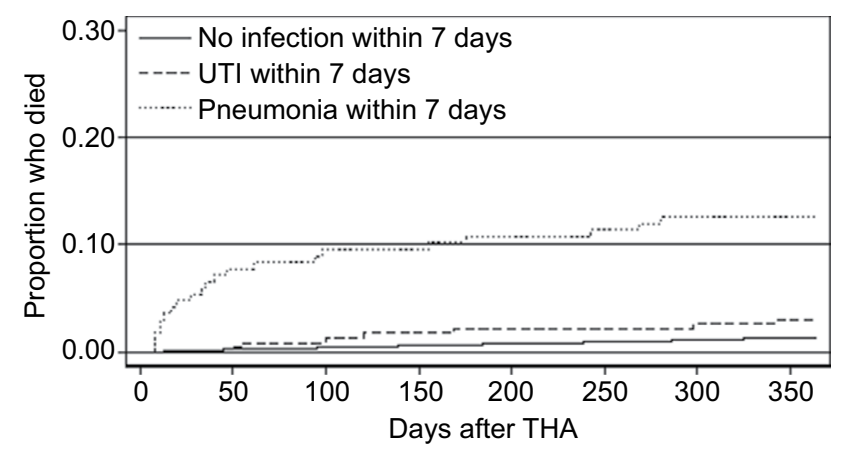

Figure 2 The cumulative mortality between 8 and 365 days after a total hip arthroplasty (THA) in patients whom did or did not develop an infection (pneumonia or urinary tract infection [UTI]) within 7 days of the primary THA.

\section{Mortality}

Within the first 7 days of the primary THA, 113 patients died. Of those, 5 had pneumonia and 1 had a UTI. In total, 326 THA patients died between 8 and 90 days. Of those who died, 14 died after developing pneumonia and 2 died after developing a UTI. The short- and long-term mortality risks and corresponding HRs are given in Table 3. The cumulative mortality within 7 days of the primary THA is illustrated in Figure 2.

\section{Discussion}

Being 80 years or older and having a comorbidity burden at the time of surgery were risk factors for both pneumonia and UTIs. In addition, we identified male gender, diabetes and COPD as risk factors for pneumonia, and female gender, an LOPH of more than 3 days, prolonged duration of surgery and a posterior approach as risk factors for UTIs. Pneumonia within the first week of a THA was a risk factor for increased mortality up to 1 year after surgery.

Major strengths of this study were the size and the use of valid public medical registers and administrative databases. Because of the public health care system in Denmark, we examined patient characteristics in an unselected population. However, an information bias in relation to pneumonia and UTIs may still be present. Despite compulsory and reimbursement related registration in the DNPR, deficient coding during the primary hospitalization is possible but presumably not related to both the covariates and mortality. The risk estimates of pneumonia and UTIs found in our study can be considered as conservative estimates. Only cases diagnosed during a primary hospitalization of 7 days or less and cases requiring readmission within 7 days were included. Pneumonia and UTIs treated by the patients' local general practitioner (GP) were not included. With a median LOPH of 3 days during the total study period, there are presumably cases of pneumonia and UTIs in this category.

Comparisons of the cumulative incidence rates of pneumonia and UTIs after THA across studies are hampered by differences in study populations, study designs, study periods, and definitions of pneumonia and UTIs. In a large register base cohort study, Bozic et al found that pneumonia within 7 days of admission occurred in $0.9 \%$ of 250,000 THA patients who were 65 years or older registered in the Medicare Enrollment Database. ${ }^{2}$ This rate is several times larger than the incidence observed in our study. The difference may, at least partially, be explained by differences in the study populations and variations in the registration practice and in the definitions of pneumonia. A comparable incidence of pneumonia was found by Huddleston et al. ${ }^{3}$ Here, the authors found a $0.3 \%$ incidence rate of pneumonia during index hospitalization in 1,809 Medicare beneficiaries treated with THA when studying risk factors for a series of medical adverse events, including both pneumonia and UTIs. ${ }^{3}$ For UTIs during index hospitalization, Huddleston et al found an incidence of $2.0 \%{ }^{3}$ The incidence of UTIs observed in the present study was lower. It is very likely 
that UTIs during the index hospitalization in our study are unrecorded. UTIs may, in many cases, manifest after discharge and therefore under the auspices of the patients' GPs. Another explanation may be differences in how a UTI was defined and how the data were captured. In the study by Huddleston et al, UTI was defined based on cultures and registered during a surveillance project determining the rates of adverse events. ${ }^{3}$ A specific focus on adverse events may have led to an increased number of identified UTIs in the study by Huddleston et al.

Both internationally and in the Danish context, there has been an increase in the incidence of pneumonia-related hospitalizations. ${ }^{12-14}$ In a Danish study, Søgaard et al found an increase in the proportion of first-time pneumonia-related hospitalizations after any surgical procedure within 30 days prior to the pneumonia admission. ${ }^{12}$ The difference in the proportions amounted to $2.5 \%$ - from $3.9 \%$ in $1997-2001$ to $6.6 \%$ in $2007-2011 .{ }^{12}$ A direct comparison with the findings by Søgaard el al is difficult and primarily hampered by the difference in surgical procedures. However, we also observed an increase in pneumonia cases during the study period. Our findings indicate that THA patients are at a lower risk of pneumonia than surgically treated patients, in general. However, the tripling in the number of pneumonia cases may indicate that the direct relationship between pneumonia and THA is a growing challenge and, therefore, further research in this field is needed.

Age and comorbidities were of importance in predicting both pneumonia and UTIs after THA. It is well known that age and comorbidities act as risk factors for both infections. ${ }^{7-9,12}$ In relation to gender, our results are in agreement with what is seen in the general population; male gender is a risk factor for pneumonia and female gender is a risk factor for UTIs. ${ }^{7,12,13}$ An LOPH of more than 3 days was identified as a risk factor for UTIs. Long hospitalizations may increase the risk of nosocomial infections but reverse causation cannot be ruled out. Frail patients have an increased risk of infections and therefore a prolonged hospitalization. The association between a shorter surgery duration and a reduced risk of UTIs after THA found in our study can be explained by the patients' earlier mobilization. In addition, shorter surgery duration may be related to the shorter use of catheters, which would reduce the risk of UTIs. We expected that prolonged surgery durations would be a risk factor of pneumonia. We do not have any clear explanations for this "missing" association aside from simple chance or early mortality in the most fragile patients before the development of pneumonia. In the unadjusted analyses, the posterior approach was a risk factor for both pneumonia and UTIs. After adjustments, only UTIs were affected. A reason for this phenomenon, although hypothetical, may be that the posterior approach requires a lateral position during surgery. A static lateral position over a prolonged period of time may affect both the respiratory passages and the lower urinary tract. Interestingly, our findings suggest a reverse association between the hospital volume and the risk of UTIs, although this relationship is not significant for all volume groups. One reason for this finding may be the more pronounced use of routine catheterization in large-volume hospitals.

Immobilization and catheterization during primary hospitalization may unquestionably be seen as independent risk factors. We know that enhanced recovery programs with the stated objective of mobilization within 4 hours after surgery are widely implemented in Denmark. ${ }^{23}$ Despite this objective, THA patients of increased age and with a high comorbidity burden may be subjects of delayed mobilization, which affects the risk of both pneumonia and UTIs. Catheterization with both indwelling catheters and intermittent catheters is used in orthopedic departments in Denmark, but the extent is unknown, and more information on the use of catheterization is very much needed. Transfusion, American Society of Anesthesiologists physical status classification, body mass index and smoking could be additional relevant covariates in relation to both pneumonia and UTIs. ${ }^{24-28}$ Unfortunately, information about these covariates was neither available in the DHR or the administrative databases nor obtained when planning the study.

Our findings of high mortality in patients who developed pneumonia may suggest that patients developing pneumonia within the first week after a THA are much more fragile and of worse general condition than patients without pneumonia, despite having the same risk pattern in relation to age, gender and their comorbidity burdens at the time of surgery. The increased long-term risk of mortality when developing pneumonia further emphasizes this hypothesis. After adjustments for gender, age and comorbidities, a 10-fold relative mortality risk in patients with pneumonia compared to patients without pneumonia seems strikingly high. Even though selection bias and unmeasured confounding partially explain this result, the finding calls for individual risk stratification before a THA. This may include involving a patient's history of pneumonia and COPD in the risk assessment before a THA and increased awareness about when pneumonia is developed. If a patient has a history of pneumonia or COPD, they may require special care during the hospitalization and early rehabilitation periods. 


\section{Conclusion}

The risks of pneumonia and UTIs within 7 days of the primary procedure were in general low; only approximately 5 out of 1,000 THA patients developed one of these infections. Age, gender and a comorbidity burden at the time of the primary procedure were the most important risk factors for pneumonia and UTIs. Pneumonia was associated with an increased mortality rate up to 1 year after surgery, despite adjusting for a number of potential confounders, including coexisting comorbidities before surgery. In particular, pneumonia may be a marker of increased fragility and unmeasured comorbidities.

\section{Author contributions}

All authors contributed to the conception of the study, study design, and the discussion and interpretation of the results. ENG drafted the article. TBH and ABP revised the manuscript for intellectual content and approved the final version before submission.

\section{Disclosure}

The authors report no conflicts of interest in this work.

\section{References}

1. Khan SK, Malviya A, Muller SD, et al. Reduced short-term complications and mortality following enhanced recovery primary hip and knee arthroplasty: results from 6,000 consecutive procedures. Acta Orthop. 2014;85(1):26-31.

2. Bozic KJ, Grosso LM, Lin Z, et al. Variation in hospital-level riskstandardized complication rates following elective primary total hip and knee arthroplasty. J Bone Joint Surg Am. 2014;96(8):640-647.

3. Huddleston JI, Wang Y, Uquillas C, Herndon JH, Maloney WJ. Age and obesity are risk factors for adverse events after total hip arthroplasty. Clin Orthop Relat Res. 2012;470(2):490-496.

4. Pugely AJ, Callaghan JJ, Martin CT, Cram P, Gao Y. Incidence of and risk factors for 30-day readmission following elective primary total joint arthroplasty: analysis from the ACS-NSQIP. JArthroplasty. 2013;28(9): 1499-1504.

5. Schairer WW, Sing DC, Vail TP, Bozic KJ. Causes and frequency of unplanned hospital readmission after total hip arthroplasty. Clin Orthop Relat Res. 2014;472(2):464-470.

6. Wroe PC, Finkelstein JA, Ray GT, et al. Aging population and future burden of pneumococcal pneumonia in the United States. J Infect Dis. 2012;205(10):1589-1592.

7. Torres A, Peetermans WE, Viegi G, Blasi F. Risk factors for communityacquired pneumonia in adults in Europe: a literature review. Thorax. 2013;68(11):1057-1065.

8. Detweiler K, Mayers D, Fletcher SG. Bacteruria and urinary tract infections in the elderly. Urol Clin North Am. 2015;42(4):561-568.
9. Sheerin NS. Urinary tract infection. Medicine. 2015;43(8):435-439.

10. Torres A, Blasi F, Peetermans WE, Viegi G, Welte T. The aetiology and antibiotic management of community-acquired pneumonia in adults in Europe: a literature review. Eur J Clin Microbiol Infect Dis. 2014;33(7): 1065-1079.

11. Murphy SL, Xu J, Kochanek KD. Deaths: final data for 2010. Natl Vital Stat Rep. 2013;61(4):1-117.

12. Søgaard M, Nielsen RB, Schønheyder HC, Nørgaard M, Thomsen RW. Nationwide trends in pneumonia hospitalization rates and mortality, Denmark 1997-2011. Respir Med. 2014;108(8):1214-1222.

13. Fry AM, Shay DK, Holman RC, Curns AT, Anderson LJ. Trends in hospitalizations for pneumonia among persons aged 65 years or older in the United States, 1988-2002. JAMA. 2005;294(21):2712-2719.

14. Trotter CL, Stuart JM, George R, Miller E. Increasing hospital admissions for pneumonia, England. Emerg Infect Dis. 2008;14(5):727-733.

15. Lucht U. The Danish Hip Arthroplasty Register. Acta Orthop Scand. 2000;71(5):433-439.

16. Pedersen A, Johnsen S, Overgaard S, Søballe K, Sørensen HT, Lucht $\mathrm{U}$. Registration in the danish hip arthroplasty registry: completeness of total hip arthroplasties and positive predictive value of registered diagnosis and postoperative complications. Acta Orthop Scand. 2004;75(4): 434-441.

17. Gundtoft PH, Varnum C, Pedersen AB, Overgaard S. The Danish Hip Arthroplasty Register. Clin Epidemiol. 2016;8:509-514.

18. Schmidt M, Schmidt SA, Sandegaard JL, Ehrenstein V, Pedersen L, Sørensen HT. The Danish National Patient Registry: a review of content, data quality, and research potential. Clin Epidemiol. 2015;7:449-490.

19. Schmidt M, Pedersen L, Sørensen HT. The Danish Civil Registration System as a tool in epidemiology. Eur J Epidemiol. 2014;29(8): 541-549.

20. Thomsen RW, Riis A, Nørgaard M, et al. Rising incidence and persistently high mortality of hospitalized pneumonia: a 10 -year populationbased study in Denmark. J Intern Med. 2006;259(4):410-417.

21. Ingeman A, Andersen G, Hundborg HH, Johnsen SP. Medical complications in patients with stroke: data validity in a stroke registry and a hospital discharge registry. Clin Epidemiol. 2010;2:5-13.

22. Charlson ME, Pompei P, Ales KL, MacKenzie CR. A new method of classifying prognostic comorbidity in longitudinal studies: development and validation. J Chronic Dis. 1987;40(5):373-383.

23. Glassou EN, Pedersen AB, Hansen TB. Risk of re-admission, reoperation, and mortality within 90 days of total hip and knee arthroplasty in fast-track departments in Denmark from 2005 to 2011. Acta Orthop. 2014;85(5):493-500.

24. Singh JA. Smoking and outcomes after knee and hip arthroplasty: a systematic review. J Rheumatol. 2011;38(9):1824-1834.

25. Bozic KJ, Lau E, Kurtz S, et al. Patient-related risk factors for periprosthetic joint infection and postoperative mortality following total hip arthroplasty in Medicare patients. J Bone Joint Surg Am. 2012; 94(9):794-800.

26. Schwarzkopf R, Thompson SL, Adwar SJ, Liublinska V, Slover JD. Postoperative complication rates in the "super-obese" hip and knee arthroplasty population. J Arthroplasty. 2012;27(3):397-401.

27. Sizer SC, Cherian JJ, Elmallah RD, Pierce TP, Beaver WB, Mont MA. Predicting blood loss in total knee and hip arthroplasty. Orthop Clin North Am. 2015;46(4):445-459.

28. Husted H, Jørgensen CC, Gromov K, Kehlet H; Lundbeck Foundation Center for Fast-track Hip and Knee Replacement Collaborative Group. Does BMI influence hospital stay and morbidity after fast-track hip and knee arthroplasty? Acta Orthop. 2016;87(5):1-7. 
Clinical Epidemiology is an international, peer-reviewed, open access, online journal focusing on disease and drug epidemiology, identification of risk factors and screening procedures to develop optimal preventative initiatives and programs. Specific topics include: diagnosis, prognosis, treatment, screening, prevention, risk factor modification,

Submit your manuscript here: https://www.dovepress.com/clinical-epidemiology-journal
Dovepress

systematic reviews, risk and safety of medical interventions, epidemiology and biostatistical methods, and evaluation of guidelines, translational medicine, health policies and economic evaluations. The manuscript management system is completely online and includes a very quick and fair peer-review system, which is all easy to use. 